\title{
Linkages for Life: Assessing Tomato Value Chain Pathways and Opportunities for Better Livelihoods of Marginal and Vulnerable Groups in Pakistan ${ }^{\dagger}$
}

\author{
Sajida Taj *, Gomathy Palaniappan and Zubair Anwar \\ Pakistan Agricultural Research Council, Islamabad 44000, Pakistan; g.palaniappan@uq.edu.au (G.P.); \\ zubairnarc@gmail.com (Z.W.) \\ * Correspondence: sajida782001@gmail.com \\ + Presented at the third International Tropical Agriculture Conference (TROPAG 2019), Brisbane, Australia, \\ 11-13 November 2019.
}

Published: 8 April 2020

\begin{abstract}
This case study offers insights into assessing tomato value chain to improving rural livelihoods of marginal and vulnerable groups in rural Punjab, Pakistan. This research is based on qualitative data collected through Focused Group Discussions (FGDs) in two pilot villages of district Muzaffargarh with men and women farmers separately. The research aims to explore the pathways, linkages and new avenues and opportunities for marginal and vulnerable groups especially women to increase their household incomes under a collaborative Pakistan-Australia Strengthening Vegetable Value Chain Project (SVVCP). It is imperative to identify effective linkages between farmers and other chain actors to have a comprehensive understanding of how these works and what roles public and private actors play in making them work more effectively to plan and implement the project activities with farmers, for farmer and by farmers. It was found that most of farming households operate less than an acre of land and supplement their income with farm labour and small businesses. Both men and women farmers indicated lack of linkages and opportunities for them besides their limited access to agricultural knowledge, skills and resources. Men have diverse linkages with male dominant institutions such as agriculture and marketing. In contrast, women have no linkages with viable economic institutions such as production and marketing and tend to be associated with domestic and community affairs. The findings suggest that, it is imperative that farmers must have access to required information and skills and opportunities for networking to build sustainable linkages with value chain actors.
\end{abstract}

Keywords: rural livelihoods; linkages; vulnerable groups; linkages; access to information; agricultural knowledge

Conflicts of Interest: The authors declare no conflict of interest.

(C) 2020 by the authors. Licensee MDPI, Basel, Switzerland. This article is an open access article distributed under the terms and conditions of the Creative Commons Attribution (CC BY) license (http://creativecommons.org/licenses/by/4.0/). 